OPEN ACCESS

Edited by:

Vikas Sood,

Jamia Hamdard University, India

Reviewed by:

Priyanka Khare,

University of Texas MD Anderson

Cancer Center, United States

Tripti Sharma,

University of Texas Southwestern

Medical Center, United States

*Correspondence:

Athanasios Alexiou alexiou@ngcef.net Gaber El-Saber Batiha

gaberbatiha@gmail.com

Specialty section: This article was submitted to Virus and Host, a section of the journal

Frontiers in Cellular and Infection Microbiology

Received: 09 March 2021 Accepted: 16 August 2021 Published: 08 September 2021

Citation:

Al-kuraishy HM, Al-Gareeb Al, Faidah $\mathrm{H}$, Alexiou A and Batiha GE-S (2021) Testosterone in COVID-19: An

Adversary Bane or Comrade Boon. Front. Cell. Infect. Microbiol. 11:666987.

do: $10.3389 /$ fcimb.2021.666987

\section{Testosterone in COVID-19: An Adversary Bane or Comrade Boon}

\author{
Hayder M. Al-kuraishy ${ }^{1}$, Ali I. Al-Gareeb ${ }^{1}$, Hani Faidah ${ }^{2}$, Athanasios Alexiou ${ }^{3,4 *}$ \\ and Gaber El-Saber Batiha ${ }^{\text {* }}$ \\ ${ }^{1}$ Department of Clinical Pharmacology and Medicine, College of Medicine, ALmustansiriyia University, Baghdad, Iraq, \\ ${ }^{2}$ Faculty of Medicine, Umm Al Qura University, Mecca, Saudi Arabia, ${ }^{3}$ Department of Science and Engineering, Novel Global \\ Community Educational Foundation, Hebersham, NSW, Australia, ${ }^{4}$ AFNP Med Austria, Wien, Austria, ${ }^{5}$ Department of \\ Pharmacology and Therapeutics, Faculty of Veterinary Medicine, Damanhour University, Damanhour, Egypt
}

COVID-19 is a pandemic disease caused by severe acute respiratory coronavirus 2 (SARSCoV-2), which leads to pulmonary manifestations like acute lung injury (ALI) and acute respiratory distress syndrome (ARDS). In addition, COVID-19 may cause extra-pulmonary manifestation such as testicular injury. Both high and low levels of testosterone could affect the severity of COVID-19. Herein, there is substantial controversy regarding the potential role of testosterone in SARS-CoV-2 infection and COVID-19 severity. Therefore, the present study aimed to review and elucidate the assorted view of preponderance regarding the beneficial and harmful effects of testosterone in COVID-19. A related literature search in PubMed, Scopus, Web of Science, Google Scholar, and Science Direct was done. All published articles related to the role of testosterone and COVID-19 were included in this mini-review. The beneficial effects of testosterone in COVID-19 are through inhibition of pro-inflammatory cytokines, augmentation of anti-inflammatory cytokines, modulation of the immune response, attenuation of oxidative stress, and endothelial dysfunction. However, its harmful effects in COVID-19 are due to augmentation of transmembrane protease serine 2 (TMPRSS2), which is essential for cleaving and activating SARS-CoV-2 spike protein during acute SARS-CoV-2 infection. Most published studies illustrated that low testosterone levels are linked to COVID-19 severity. A low testosterone level in COVID-19 is mainly due to testicular injury, the primary source of testosterone.

Keywords: anti-inflammatory cytokines, COVID-19, pro-inflammatory cytokines, testosterone, TMPRSS2

\section{INTRODUCTION}

The novel coronavirus disease 19 (nCoV19), commonly known as COVID-19, is an infectious disease caused by severe acute respiratory coronavirus 2 (SARS-CoV-2), leading to acute systemic disturbances, pro-inflammatory activation, hypercytokinemia, cytokine storm, and multi-organ damage (Al-Kuraishy et al., 2020). COVID-19 affects various organs, mainly the respiratory system, presenting with pulmonary manifestations like acute lung injury (ALI) and acute respiratory distress syndrome (ARDS), and extra-pulmonary manifestations like acute cardiac, neurological disorders, pancreatic injury, acute kidney injury, and testicular injury (Al-Kuraishy et al., 2020a; 
Lugnier et al., 2021). This systemic effect of COVID-19 is due to the wide distribution of angiotensin-converting enzyme 2 (AEC2), a receptor and entry point for SARS-CoV-2 (AlKuraishy et al., 2020b). ACE2 receptor is chiefly expressed in the lung alveolar cells type II, proximal renal tubules, and testis primarily in Sertoli and Leydig cells. Binding of SARS-CoV-2 to ACE2 leads to downregulation of these protective receptors with subsequent increment in the level of vasoconstrictors angiotensin II (Ang II) and reduction of vasodilator angiotensin (Ang 1-7) (Ang 1-9) with induction release of pro-inflammatory cytokines (Bank et al., 2021).

Since the World Health Organization (WHO) declaration of this disease as a pandemic and until late July 2021, the total confirmed cases are 194,250,977, with 4,258,789 deaths. The mortality rate ranges from $0.9 \%$ to $10.5 \%$ in COVID- 19 patients without comorbidities than COVID-19 patients with comorbidities, respectively (Anjorin et al., 2021).

It has been reported that male sex is regarded as a risk factor for COVID-19 severity and had worse outcomes, which might occur due to male-specific factors that increase men's vulnerability to the SARS-CoV-2 infection compared to women (Farghaly and Makboul, 2021). One of the important male sex-specific factors is the anabolic testosterone hormone secreted mainly from testicles and to a lesser extent from the adrenal cortex (Al-Maiahy et al., 2020). Testosterone is also secreted from ovaries in females; however, the total daily testosterone production is approximately 20 times more in males than in females; thus, testosterone serum level is 8 times more in men than in women (Handelsman et al., 2018).

Testosterone serum levels are reduced on average by $2 \%$ per year after the age of 40 years, increasing the prevalence of hypogonadism in men following the age of 40 years up to $9.5 \%$, and this prevalence is augmented in several cardiometabolic disorders (Grossmann et al., 2020). Indeed, testosterone deficiency-induced late hypogonadism is regarded as an independent risk factor for various pulmonary disorders and cardio-metabolic disturbances, including hypertension, dyslipidemia, type 2 diabetes mellitus (T2DM), endothelial dysfunction, and coagulopathy (Butanis et al., 2017; Assyov et al., 2020). Therefore, hypogonadism accounts for $53.3 \%$ of hospitalized patients with a high mortality rate due to immunosuppression and susceptibility for different viral infections (Pezzaioli et al., 2020).

During COVID-19, SARS-CoV-2 infection may affect the testicles by binding to ACE2 expressed in the Sertoli and Leydig cells, causing infertility and suppressing testosterone production (Abobaker and Raba, 2020). Schroeder et al. (2020) illustrated that low testosterone serum level is linked to SARS-CoV-2 infections and COVID-19 severity in critically ill patients due to reduced immunomodulation antiviral effects of androgen. On the other hand, Wambier et al. (2020) revealed that high testosterone and other androgens serum levels might increase the severity of COVID-19 through augmentation of the expression of transmembrane protease serine 2 (TMPRSS2), which is vital for cleaving and activation of SARS-CoV-2 spike protein during acute SARS-CoV-2 infection.
Therefore, there is substantial controversy regarding the potential role of testosterone and other androgens in SARSCoV-2 infection and COVID-19 severity. Thus, the present study is aimed to review and elucidate the assorted view of preponderance regarding testosterone's beneficial and harmful effects in COVID-19.

\section{METHODS AND SEARCH STRATEGY}

A related literature search in PubMed, Scopus, Web of Science, Google Scholar, and Science Direct was done. All published articles related to the role of testosterone and COVID-19 were included in this mini-review. We search the international database using the medical subject heading $(\mathrm{MeSH})$ to identify the relevant articles published up to 2021. The listed keywords used in this search included [COVID-19 OR SARS-CoV-2] AND [Testosterone OR Androgens], [COVID-19 OR SARS-CoV-2] AND [Hypogonadism OR Androgen sensitivity], [Hypogonadism OR Low testosterone], AND [COVID-19 severity]. The final results were mainly limited to human subjects. All types of published articles with different languages were included, and the final findings were summarized in a mini-review (Figure 1).

\section{THE BENEFICIAL ROLE OF TESTOSTERONE IN COVID-19}

It has been reported that testosterone serum level is reduced by aging and cardio-metabolic diseases including T2DM, obesity, dyslipidemia, heart failure, and atherosclerosis, which are common risk factors for the development of COVID-19 severity (Millar et al., 2016; Maddaloni et al., 2020).

Different studies illustrated that testosterone has a protective role in the respiratory system; it improves forced expiratory volume, vital capacity, oxygen consumption, and respiratory muscle contraction (Montano et al., 2014). Marques et al. (2020) illustrated that testosterone replacement therapy in orchiectomized male rats improves oxygenation and attenuates tissue hypoxia and hypercapnia. Thus, low testosterone serum levels in patients with hypogonadism may increase severity of obstructive pulmonary disease (Novković et al., 2019).

\section{Testosterone and Acute Lung Injury}

Testosterone has a crucial pulmo-protective effect through the modulation of lung inflammations, and a reduction of testosterone by aging may predispose the old age for chronic inflammatory pulmonary disorders and viral infections (Keilich et al., 2019). Redente et al. (2011) illustrated that testosterone's defending role against bleomycin-induced ALI is through inhibition of proinflammatory mediated neutrophil alveolitis. It has been observed that testosterone inhibits the production of proinflammatory cytokines, including IL- $1 \beta$, IL- 6 , and TNF- $\alpha$, and inflammatory adipocytokines with a cumulative effect on the anti- 


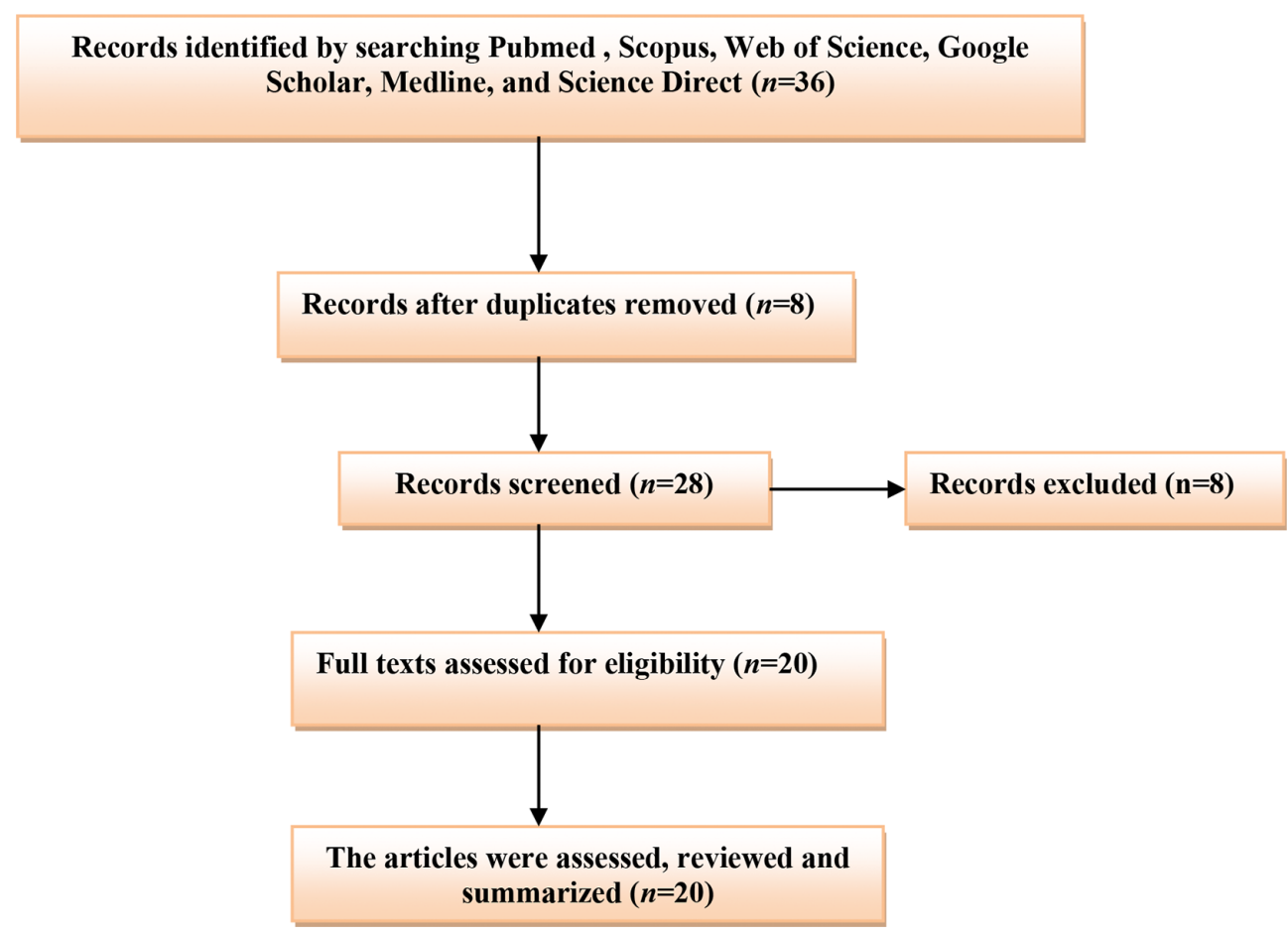

FIGURE 1 | Consort-flow diagram of the present study.

inflammatory adiponectin (Bianchi, 2019). Wang et al. (2021) revealed that testosterone therapy reduces lung inflammation and fibrosis by inhibiting nuclear respiratory factor 1 (NRF1) and the NF- $\kappa B$ signaling pathway.

Pro-inflammatory cytokines, mainly IL-6, are involved in the pathogenesis of ALI, ARDS, and cytokine storm-induced multiorgan damage in COVID-19 (Sun et al., 2020). Typically, testosterone inhibits the synthesis and release of IL-6 and downregulates the expression of IL-6 receptors (Sun et al., 2020). Thus, IL-6 serum level is augmented in hypogonadism patients that increase their susceptibility for COVID-19 severity (Papadopoulos et al., 2020). Besides, adiponectin, through its anti-inflammatory effects, may reduce SARS-CoV-2-induced pro-inflammatory hypercytokinemia and associated ALI (Messina et al., 2020).

Of note, activation of nod-like receptor pyrin 3 (NLRP3) inflammasome is linked to over-activation of NF- $\mathrm{KB}$ signalinginduced inflammatory reactions in COVID-19. Activation of NLRP3 inflammasome is also related with COVID-19 severity and associated complications like ALI and ARDS (van den Berg and Te Velde, 2020). Chen et al. (2020) in their experimental study confirmed that testosterone therapy reduces atherogenesis by suppressing NLRP3 inflammasome. However, Alves et al. (2020) showed that supra-physiological testosterone level leads to oxidative stress-induced endothelial dysfunction and vascular injury through stimulation of NLRP3 inflammasome. Previously, Vignozzi et al. (2012) disclosed that testosterone through its derivative dihydrotestosterone suppresses NF- $\kappa \mathrm{B}$ signaling activation and associated proinflammatory activations. Therefore, testosterone therapy may improve the clinical outcomes in COVID-19 patients through NLRP3 inflammasome/NF- $\mathrm{BB}$-dependent activation of anti-inflammatory cytokines and suppression of proinflammatory cytokines.

A prospective study involving 221 hospitalized men with COVID-19 pneumonia aged > 18 years illustrated that testosterone serum levels are reduced and correlated with COVID-19 severity and mortality (Çayan et al., 2020). Similarly, low baseline total and free testosterone in 31 COVID-19 patients recovered from ARDS in Italy are negatively correlated with inflammatory risk factors (ferritin, CRP procalcitonine, and D-dimer) and linked to COVID-19 severity (Rastrelli et al., 2020). Likewise, an observational study in Germany involving 45 COVID-19 patients revealed that $70 \%$ of them have low testosterone at the time of admission with subsequent reduction through ARDS development and admission to the intensive care unit (ICU) (Schroeder et al., 2020). Furthermore, a prospective study composed of 358 men with COVID-19 compared with 92 negative for COVID-19 illustrated that testosterone levels are reduced in COVID-19 patients and linked to poor clinical outcomes (Cinislioglu et al., 2021). In addition, a retrospective study showed that low testosterone level is connected with COVID-19 severity and risk of death (Okçelik, 2021). Low testosterone serum level is associated with reduction of body anti-inflammatory capacity with augmentation of pro-inflammatory axis. High pro- 
inflammatory cytokines in turn suppress release and action of testosterone in a vicious cycle manner (Bianchi, 2019).

Furthermore, the receptor for advanced glycation end-product (RAGE) is a member of immunoglobulin superfamily protein, which presents in two forms, membrane RAGE (mRAGE) and soluble RAGE (sRAGE) (Papadopoulos et al., 2020). mRAGE has an inflammatory effect through activation of NF-kB, while sRAGE has anti-inflammatory effects through upregulation of ACE2 and anti-inflammatory cytokines (Serveaux-Dancer et al., 2019). RAGE pathway is mainly expressed in lung tissue and linked to the development of acute and chronic lung injuries (Wang et al., 2018). It has been shown that SARS-CoV-2 activates mRAGE at pulmonary alveolar cells, leading to severe inflammatory reactions (Yalcin Kehribar et al., 2020). It has been confirmed that the concentration of sRAGE is reduced with aging, which might explain the susceptibility of old age to COVID-19 (Evens et al., 2020). However, in young and asymptomatic COVID-19 patients, the concentration of sRAGE is high. In severe COVID-19, sRAGE level is significantly reduced, so low sRAGE level is associated with progression of ALI and ARDS (Abbasi-Oshaghi et al., 2021).

Therefore, COVID-19-induced reduction in circulating testosterone may induce ALI due to increase of proinflammatory and reduction anti-inflammatory effects.

\section{Testosterone and Testicular Injury}

In COVID-19, SARS-CoV-2 may bind testicle ACE2, leading to Sertoli and Leydig cells' damage with subsequent inhibition of testicular testosterone synthesis (Illiano et al., 2020). Also, local inflammatory reaction in the testes due to SARS-CoV-2 infection and deregulation of the testicular renin-angiotensin system (RAS) may also impair testicular testosterone synthesis leading to hypogonadism (Yang et al., 2020). Analysis of testicular biopsies in patients with COVID-19 illustrated that the histopathological changes like hypoxic injury and microthrombosis are similar to that observed in COVID-19-induced ALI. However, SARS-CoV-2 was not detected in the injured testes, suggesting oxidative stress; coagulation disorders might mediate this damage as evident in COVID-19 pneumonia (Flaifel et al., 2021).

Therefore, preexistence or SARS-CoV-2-induced hypogonadism may reduce the protective effect of testosterone against SARS-CoV-2 infection, suggesting a link between testicular injury and development of ALI and ARDS in COVID-19 patients (Yang et al., 2020; Zaim et al., 2020). Moreover, high pro-inflammatory cytokines in SARS-CoV-2 infection may induce endothelial dysfunction and coagulopathy, a hallmark in COVID-19. The prothrombotic status and risk of thromboembolism are highly aggravated in hypogonadism (Fei et al., 2020). Local testicular thrombosis during SARS-CoV-2 infection is associated with diffuse damage of Leydig and Sertoli cells (Duarte-Neto et al., 2021). However, testosterone supplementation improves endothelial function via activation of nitric oxide release, inhibiting platelet activations and pro-thrombotic cascades (Hotta et al., 2019).

These clinical studies illustrated that reduction in the testosterone level is due to testicular injury with a subsequent reduction in the synthesis and release of testosterone from Leydig cells. This simple explanation is not acceptable since testicular injury is not frequently involved during SARS-CoV-2 infections (Schroeder et al., 2020). However, total testosterone may reduce in COVID-19 in the absence of testicular injury, as $90 \%$ of COVID-19 patients have a negative test for SARS-CoV-2 in the testes (Yang et al., 2020). A recent study illustrated that hypogonadism is developed in the early phase of COVID-19 due to SARS-CoV-2-induced testicular injury (Dutta and Sengupta, 2021). Higher expression of ACE2 in the testes makes them a potential target for SARS-CoV-2 with subsequent progression of male infertility. Excessive production of reactive oxygen species by SARS-CoV-2 may disrupt sperm function and morphology leading to early- or late-onset infertility (Esteves et al., 2021). Xu et al. (2021) showed that despite testicular injury during acute SARS-CoV-2 infection, male sex hormones remain unchanged even after recovery from COVID-19. Herein, extensive molecular studies are recommended to observe the implication of SARS-CoV-2 infections in reducing testosterone levels in COVID-19 patients. Zhao et al. (2016) illustrated that activation of mRAGE is correlated with inhibition of Leydig cell function with reduction of testosterone biosynthesis. This finding might explain low testosterone levels in patients with severe COVID-19.

In COVID-19, downregulation of lung ACE2 by SARS-CoV-2 is associated with high circulating AngII level, which is linked to development and progression of ALI and ARDS (Zhang et al., 2020). It has been confirmed that AngII inhibits Leydig cell function and testosterone synthesis (Reis and Reis, 2020). Add to these findings, the testes have full RAS, which is involved in the regulation function of Leydig cells and testosterone biosynthesis (Reis and Reis, 2020). Thus, systemic or testicular AngII levels are augmented due to downregulation of ACE2 in COVID-19. Local and circulating AngII activate harmful AT1R on the Leydig cells leading to the inhibition of testosterone biosynthesis (Pascolo et al., 2020). The deregulation of the protective AT2R and Mas receptors within the testes provokes inflammatory cascades that also contribute to Leydig cells' dysfunction (Aitken, 2020; Pascolo et al., 2020). From the above considerations, AngII might be the potential biomarker linking ALI and testicular injury in patients with severe COVID-19.

\section{Testosterone and Oxidative Stress}

Additional studies illustrated that SARS-CoV-2 infection leads to oxidative stress injury and oxidative storm due to membrane lipid and protein peroxidations (Ntyonga-Pono, 2020). The high neutrophil ratio in SARS-CoV-2 infection is linked to high oxidative stress due to the production of reactive oxygen species (ROS) by neutrophils. These changes provoke a cascade of immuno-biological events that the human body responds to (Ntyonga-Pono, 2020). ROS causes various pathological events related to COVID-19, such as endothelial dysfunction, erythrocyte injury, platelet activation, and thrombosis (Laforge et al., 2020). High ROS in COVID-19 promotes neutrophil extracellular traps (NETs) and induction release of pro- 
inflammatory cytokines (Laforge et al., 2020). NETs activate NLRP3 inflammasome, NF- $\kappa \mathrm{B}$, and induction of coagulopathy (Schönrich et al., 2020).

It has been reported that oxidative stress inhibits testosterone biosynthesis through activation of mitogen-activated protein kinase p38 (MAPK), which alter the metabolic process and gene expression (Shi and Dansen, 2020). Therefore, severe oxidative stress upregulates the p38MAPK pathway in the Leydig cells causing significant inhibition of testicular testosterone biosynthesis (Han et al., 2018). Recently, Jing et al. (2020) confirmed that oxidized low-density lipoprotein (oxLDL) inhibits testosterone synthesis through induction of p38MAPK pathway in the Leydig cells.

Oxidative stress inhibits Leydig and adrenal cells to synthesize testosterone through upregulation of cyclooxygenase 2 (COX2), induced by the p38MAPK pathway (Martin and Touaibia, 2020). Both p38MAPK pathway and COX2 are activated in COVID-19; Grimes and his colleague (Grimes and Grimes, 2020) illustrated that SARS-CoV-2 might directly or indirectly activate the p38MAPK pathway through downregulation of ACE2 and augmentation of AngII. Besides, activation of proinflammatory cytokines in COVID-19 induces upregulation of COX2 (Ong et al., 2020). Zhoa et al. (2019) confirmed that the $\mathrm{NF}-\kappa \mathrm{B}$ signaling pathway mediates the interaction between the p38MAPK pathway and COX2 in reducing testicular testosterone biosynthesis. In addition, activated p38MAPK provokes blood-testes barrier injury by suppressing testicular spermatogenesis and testosterone biosynthesis (Liu et al., 2018). Therefore, SARS-CoV-2 infection may reduce circulating testosterone and induces hypogonadism through activation of the p38MAPK/COX2 axis.

Into the bargain, testosterone inhibits neutrophil oxidative stress by reducing the production of superoxide anion, inhibition of lipid peroxidation, and improvement of glutathione reductase activity (Marin et al., 2010). In addition, an experimental study revealed that testosterone improves testes antioxidant potential by which it may attenuate oxidative stress-induced testicular injury (Aydilek et al., 2004).

Therefore, testosterone may reduce COVID-19 severity through mitigation of SARS-CoV-2-induced oxidative stress and associated complications.

\section{Testosterone and Macrophage Function}

Moreover, SARS-CoV-2 infection may lead to macrophage activation syndrome (MAS), which is characterized by hemophagocytosis, pancytopenia, coagulopathy, and disseminated intravascular coagulation (DIC). The MAS is developed in different viral infections including SARS-CoV-2 due to imbalanced release of pro-inflammatory cytokines (McGonagle et al., 2021). Of note, testosterone has an important regulatory role on the macrophage, monocyte, and T-cell functions. Testosterone inhibits release of proinflammatory and inflammatory cytokines from immune cells (Bereshchenko et al., 2018). Testosterone therapy was shown to prohibit release of pro-inflammatory cytokines from monocytes mainly in hypogonadal men compared with eugonadal one (Bianchi, 2019). In addition, testosterone decreases the expression and sensitivity of macrophage TLR4 for its ligand (Rettew et al., 2008). Of interest, TLR4 mediates early immunological interaction of SARS-CoV-2 with macrophage and other immune cells (Aboudounya and Heads, 2021). Therefore, testosterone therapy in COVID-19 patients may interrupt macrophage activation, exaggerated immune response, and development of MAS.

Furthermore, testicular macrophages (TMs) have immunoregulatory and immunotolerant functions as well as control of testicular steroidogenesis and spermatogenesis (Meinhardt et al., 2018). During sepsis and pathogen invasion, the classical type macrophage (M1) is activated and induces release of local pro-inflammatory cytokines. These cytokines impair spermatogenesis with significant inhibition of testicular steroidogenesis. The alternative type macrophage (M2) has local anti-inflammatory action supporting spermatogenesis and release of testosterone from Leydig cells (Chen et al., 2018; Meinhardt et al., 2018).

In SARS-CoV-2 infection, macrophage polarization is toward M1 phenotype resulting in testicular injury with impairment of testicular steroidogenesis and spermatogenesis (Lv et al., 2021). Becerra-Diaz et al. (2018) illustrated that testosterone and other androgens through macrophage androgenic receptor (AR) enhance M2 polarization with domination of macrophage antiinflammatory effect. Taken together, testosterone modulates macrophage functions in general and more specifically TMs, by which it reduces the harmful effects of SARS-CoV-2 infection on the testes.

\section{Testosterone Versus Estrogen in Men}

In general, women have a robust immune system as compared to men due to the protective effect of estrogen against immunological dysregulation during different viral infections (Priyanka and Nair, 2020). It has been shown that estrogen has complex immunomodulating effects, and its effect on the inflammatory milieu in COVID-19 has been suggested (Ma et al., 2021). High estrogen serum level in premenopausal women might be a protective factor against COVID-19 severity, though older post-menopausal women are of high risk for development of COVID-19 severity compared to elderly men (Ciarambino et al., 2021). Nevertheless, reduction of estrogen level in later life in women does not appear to play a harmful role regarding COVID-19 severity in elderly women (Papadopoulos et al., 2021). In elderly men, there is significant reduction of testosterone with elevation of estrogen level due to increasing aromatization of adrenal and testicular androgens (Jardí et al., 2018). However, during sepsis in men, there is a noteworthy reduction of testosterone level with parallel increase of estrogen that reflects negative outcomes in septic men (Bech et al., 2020).

Thus, administration of estrogen in men with COVID-19 may offer a potential protective effect against COVID-19 severity (Suba, 2020). Bukowska et al. (2017) confirmed from experimental data that estrogen is able to regulate expression of the ACE/ACE2 axis, which is highly distorted in COVID-19. Also, estrogen inhibits propagation of cytokine storm and can activate B cells for antibody production. Besides, estrogen reduces expression of TMPRSS2, thereby reducing the entry of 
SARS-CoV-2 to the susceptible cells (Bennink et al., 2021). So, estrogen treatment is suggested to be an effective treatment against COVID-19 (Bennink et al., 2021).

These findings highlighted the potential protective effects of testosterone against SARS-CoV-2 infection (Table 1). However, reduction of total testosterone level in COVID-19 is due to complex interactions between SARS-CoV-2 with oxidative stress, pro-inflammatory cytokines, and systemic and local RAS (Figure 2).

\section{HARMFUL ROLE OF TESTOSTERONE IN COVID-19}

\section{Testosterone and TMPRSS2 in COVID-19}

Various studies illustrated that men's higher predisposition to develop severe and serious COVID-19 complications is related to sex hormones, mainly testosterone and sociocultural factors (Lipsky and Hung, 2020). It has been confirmed that TMPRSS2 is required for proteolytic activation and priming of SARS-CoV-2 spike protein to bind ACE2 (Rahman et al., 2020). The expression of the TMPRSS2 gene is promoted by testosterone hormone, which might explain the severity of COVID-19 in men due to facilitating the entry of SARS-CoV-2 (Stopsack et al., 2020). TMPRSS2 is a cellular enzyme encoded by the human TMPRSS2 gene involved in prostatic cancer (Mehra et al., 2007) and cleaving of hemagglutinin viral antigen and infectivity of HIN1 and H7N9 influenza virus (Cheng et al., 2015). The TMPRSS2 gene is expressed in different tissues including lung and testes (Shen et al., 2020).

In addition to the androgen, nicotine smoking increases the expression of the TMPRSS2 gene, which might explain the severity of COVID-19 severity in nicotine smoker patients (Voinsky and Gurwitz, 2020). However, various studies reported the protective effect of nicotine smoking against SARS-CoV-2 due to different mechanisms, including upregulation of lung ACE2, antiinflammatory, and immunosuppressive effects through activation of nicotinic acetylcholine receptor type 7 alpha (nAChR7 $\alpha$ ) on the macrophage (Farsalinos et al., 2020). Likewise, Donlan et al. (2020) observed that the expression of the TMPRSS2 gene is activated by IL-13, a highly expressed cytokine in COVID-19 and regarded as a predictive factor for mechanical ventilation independent of gender, age, and comorbidities. Besides, TMPRSS2 is highly co-expressed with furin, cathepsin L and B, CD209, and CD147 in men only, while co-expression with ACE2 is similar in both sexes (Piva et al., 2021). Certainly, TMPRSS2 co-expression with CD147 is important since CD147 is regarded as an entry point for SARSCoV-2 (Radzikowska et al., 2020). Furthermore, Cao et al. (2017) in their experimental study confirmed that testosterone therapy increases the expression of CD147.

Therefore, overexpression of TMPRSS2 by androgen may implicate the testosterone in the pathogenesis of SARS-CoV-2 infection and COVID-19 severity. Thereby, TMPRSS2 inhibitors such as bromhexine, aprotinin, camostat, and nafamostat are useful in managing COVID-19 through attenuation of TMPRSS2-dependent lung inflammation, coagulopathy, and development of ARDS (Azimi, 2020; Breining et al., 2020). Indeed, the population-based study of Montopoli et al. (2020) that involved 9,280 COVID-19 patients with or without prostatic cancer illustrated that patients receiving androgen deprivation therapy (ADT) are at a lower risk for COVID-19-related complications compared to patients who did not receive ADT. This finding suggests that the anti-androgen agents reduce testosterone's activation role on the expression of TMPRSS2, and thus high testosterone level may increase COVID-19 severity. Adamowicz et al. (2020) showed that high dihydrotestosterone level is linked to poor pulmonary outcomes in COVID-19 patients, though use of 5- $\alpha$ reductase inhibitors may aggravate COVID-19 severity due to disturbance of intra-pulmonary androgen metabolism. However, McCoy et al. (2020) showed that using 5- $\alpha$ reductase inhibitors is associated with good clinical outcomes in COVID-19 patients.

Moreover, different therapeutic modalities such as dexamethasone, nitric oxide, and chloroquine, which are effective in managing COVID-19, are reported to have antiandrogenic effects and suppression of TMPRSS2 (Cronauer et al., 2007; Guo et al., 2018; Chi et al., 2020). Taken together, based on the current findings, testosterone is implicated in the facilitation of SARS-CoV-2 infection through upregulation of TMPRSS2 and androgen receptor (AR) activation.

TABLE 1 | Beneficial effects of testosterone in COVID-19.

\begin{tabular}{lll}
\hline References & \multicolumn{1}{c}{ Study type } & \\
\hline Margue et al. (Marques et al., 2020) & Experimental study & Testosterone improves oxygenation and attenuates tissue hypoxia. \\
Wang et al. (2021) & Experimental study & Testosterone therapy reduces lung inflammation and fibrosis. \\
Bianch (Sun et al., 2020) & Systematic review & Testosterone inhibits the synthesis and release of IL-6. \\
Chen et al. (2020) & Experimental study & Testosterone therapy inhibits NLRP3 inflammasome. \\
Vignozzi et al. (2012) & Prospective study & Testosterone suppresses NF- $\mathrm{kB}$ signaling. \\
Cayan et al. (Çayan et al., 2020) & Cohort study & Testosterone serum levels are reduced and correlated with COVID-19 severity and mortality. \\
Rastrelli et al. (2020) & Cohort study & Testosterone serum level is negatively correlated with inflammatory risk factors \\
Schroder et al. (Rastrelli et al., 2020) & Cohort study & 70\% of COVID-19 patients have low testosterone at the time of admission. \\
Cinislioglu et al. (2021) & Prospective study & Testosterone levels are reduced in COVID-19 patients and linked to poor clinical outcomes. \\
Okcelik et al. (Okçelik, 2021) & Retrospective study & Low testosterone level is connected with COVID-19 severity and risk of death. \\
Hota et al. (Hotta et al., 2019) & Systematic review & Testosterone supplementation improves endothelial function. \\
Marin et al. (2010) & In vitro study & Testosterone inhibits oxidative stress. \\
Bereshchenko et al. (2018) & Systematic review & Testosterone inhibits release of pro-inflammatory and inflammatory cytokines from immune cells.
\end{tabular}




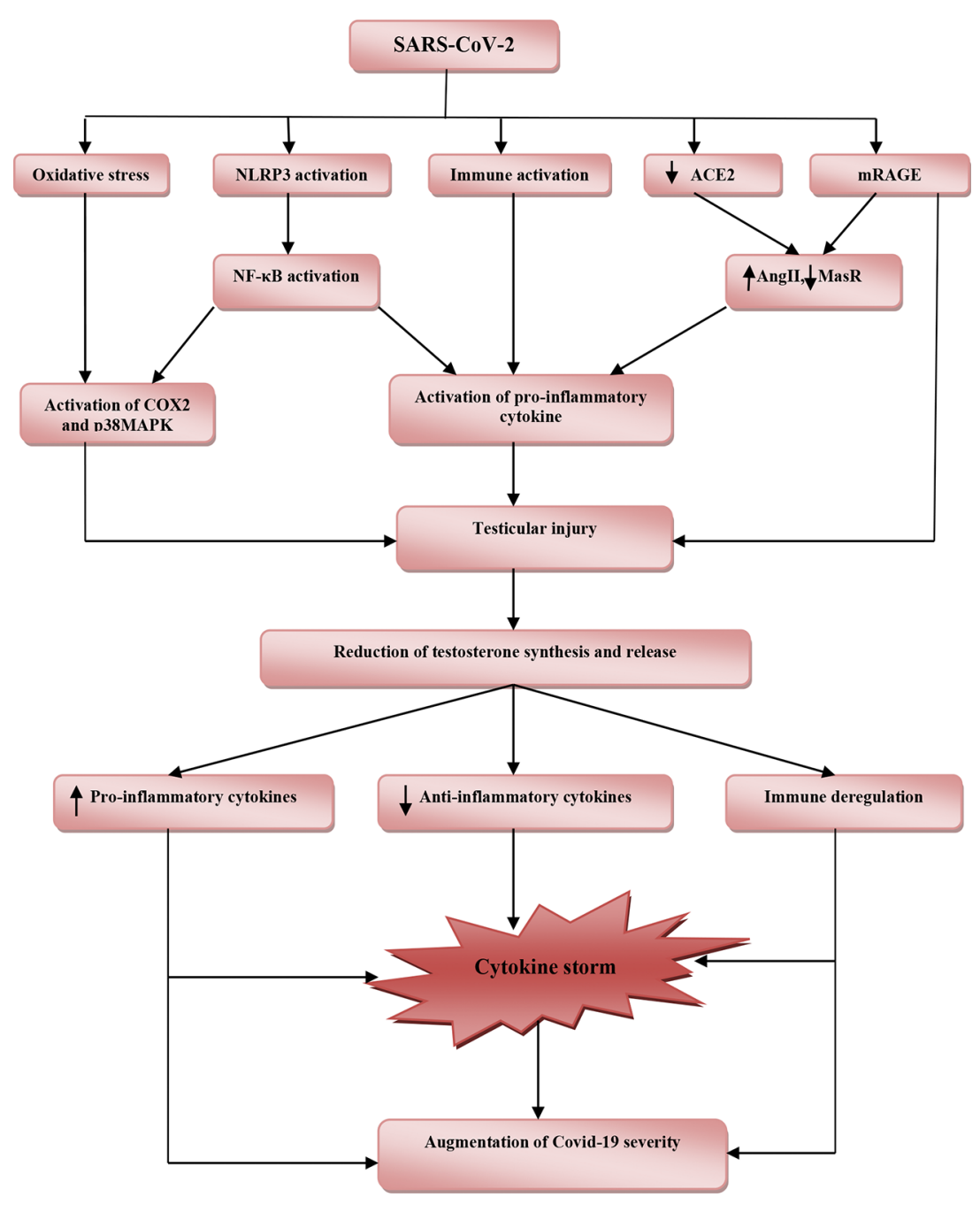

FIGURE 2 | The potential role of SARS-CoV-2 infection in the reduction of testosterone and associated COVID-19 severity. SARS-CoV-2 induces oxidative stress, activation of nod-like receptor pyrin-3 (NLRP3) inflammasome and abnormal immune activation, downregulation of angiotensin converting enzyme 2 (ACE2), and activation of receptor for advanced glycation end-product (mRAGE). Downregulation of ACE2 with activation of mRAGE increases angiotensin II (Angll) and reduces Mas receptor (MasR). Activation of NLRP3 inflammasome triggers release of nuclear factor kappa B (NF-kB) and together with cyclooxegenase-2 (COX-2) and p38 mitogen-activated protein kinase (p38MAPK) stimulate release of pro-inflammatory cytokines, which cause testicular injury. These pathophysiological changes reduce production and release of testosterone from injured testes. Reduction in the level of testosterone provokes releases of pro-inflammatory cytokines and reduces antiinflammatory cytokines with immune deregulation. These changes lead to induction of cytokine storm with consequent augmentation of COVID-19 severity.

\section{Androgen Sensitivity and COVID-19}

The role of androgen sensitivity and polymorphism in COVID-19 is explained by different studies. It has been reported that a low mortality rate in pre-pubescent compared to the high mortality rate in adult men during the COVID-19 pandemic is due to low androgen sensitivity (Wambier et al., 2020). In addition, men with androgenic alopecia and women with polycystic ovary syndrome are at a higher risk for SARS-CoV-2 infection and COVID-19 severity due to higher androgen sensitivity. Therefore, the higher mortality rate for COVID-19 in the African American population is related to the polymorphism and higher sensitivity of androgenic receptors (Goren et al., 2020).
It has been known that the polyglutamine (poly-Q) tract of the AR affects the physiological response of circulating testosterone (Callewaert et al., 2003). Longer poly-Q of AR reduces the sensitivity to testosterone and is associated with high testosterone serum level because of impairment of negative feedback inhibition (Mohamad et al., 2018). In addition, longer poly-Q of AR is linked to activation of pro-inflammatory axis (Pierotti et al., 2010), although AR with short poly-Q has protective and anti-inflammatory roles in COVID-19 regardless of testosterone serum levels (Baldassarri et al., 2021). Therefore, testosterone may have bidirectional effects depending on the underlying length of AR poly-Q tract. 
The distribution of poly-Q allele differs among diverse populations: longer in Asians, medium in Caucasians, and shorter in Africans (Ackerman et al., 2012). This might explain the high mortality in the first wave of SARS-CoV-2 infection in both China and Italy (Pereira et al., 2020). Of interest, African populations are more prone to the SARS-CoV-2 infection due to higher sensitivity of AR and higher expression of the TMPRSS2 gene (de Lusignan et al., 2020).

Therefore, AR sensitivity and length of poly-Q tract of AR seem to be more important than testosterone level in the prediction of COVID-19 severity. Besides, testosterone therapy in patients with COVID-19 may improve or worsen the clinical outcomes depending on patient AR sensitivity (Mukherjee and Pahan, 2021).

\section{Immunological Effects of Testosterone in COVID-19}

It has been reported that both adaptive and innate immune systems are crucial for contrasting viral infections and enhancing viral clearance and tissue repair (Kikkert, 2020). Giagulli et al. (2021) illustrated that circulating testosterone has immunosuppressive effects by inhibiting $\mathrm{B}$ and $\mathrm{T}$ cells, impairing immune response and immunoglobulin generations in different viral infections (Ghosh and Klein, 2017). In COVID19, natural killer, B, and T cells are reduced; specifically reducing CD8 $\mathrm{T}$ cell is regarded as an independent predictor for severe COVID-19-related complications (Wang et al., 2020). Kissick et al. (2014) revealed that testosterone inhibits differentiation of CD4 $\mathrm{T}$ cells, providing a basis for targeting testosterone and other androgenic receptors to mitigate CD4 T-cell response in various forms of autoimmune disorders.

Several lines of evidence from various studies point to the immunosuppressive potential role of testosterone on various components of the immune system (Gubbels Bupp and Jorgensen, 2018), although the basic molecular mechanism is still not elucidated. Testosterone mediated downregulation of systemic immune response through cell-type-specific effects in many immunological disorders (LaVere et al., 2021). The precise immunological effects of testosterone and other androgens are through inhibition of antibody response to the viral infections and vaccines, suppression of macrophages and dendritic cells, promotion of immunological tolerance via activation of regulatory $\mathrm{T}$ cells, and inhibition of functions and developments of $\mathrm{B}$ and $\mathrm{T}$ cells (Trigunaite et al., 2015). Regarding these considerations, men are more vulnerable for COVID-19 severity as compared with women due to the immunosuppressive effects of testosterone (Bwire, 2020). Testosterone enhances both secretion and production of Th1-to-Th2 cytokine ratio via stimulated $\mathrm{T}$ cells and reduces humoral response and B-cell proliferation (Roved et al., 2017).

Moreover, the lysophosphatidyl serine receptor (GPR174) encoded by X-chromosome gene is highly expressed on B and $\mathrm{T}$ cells in women compared with men (Barnes et al., 2015). GPR174 regulates and controls the release of pro-inflammatory cytokines, B-cell migration, and macrophage polarization in septic shock and in response to chemokines (Qiu et al., 2019).
These verdicts and results highlighted testosterone's potential immunosuppressive effect in the progression of SARS-CoV-2 infection and COVID-19 severity (Salonia et al., 2021). Therefore, ADT might be a therapeutic opportunity against COVID-19 by reversal of immunosuppression status (Montopoli et al., 2020).

\section{Metabolic Effects of Testosterone in COVID-19}

Testosterone has a permissive effect for circulating AngII by expressing AT1R and downregulation of ATR2 with a higher ATR1R/AT2R ratio. However, castration reverses this ratio (Mishra et al., 2019). High circulating AngII and ATR1R expression are linked to ALI and ARDS development in COVID-19 (Wu et al., 2020). Besides, a high AngII level induces testicular injury and cell apoptosis with the reduction of Leydig cells for the synthesis of testosterone (Wang et al., 2017). Thus, in SARS-CoV-2 infection, there is a vicious cycle conflict in the interaction between testosterone and AngII concerning the lung-testis axis in severe COVID-19.

To date, dipeptidyl peptidase 4 (DPP4), which is highly expressed in different tissues, mainly in lung type II alveolar cells, is regarded as an entry point for SARS-CoV-2 and is associated with poor clinical outcomes in COVID-19 patients (Solerte et al., 2020). Blauschmidt et al. (2017) observed that testosterone upregulates the expression of DPP4 receptors in women with polycystic ovary syndrome. DPP4 inhibitors effectively manage COVID-19 through modulation of the antiinflammatory/pro-inflammatory axis (Mirani et al., 2020). Thus, testosterone may increase COVID-19 severity through the DPP4/CD26 pathway; however, there is no study related to DPP4/CD26 and testosterone in SARS-CoV-2 infection.

Moreover, obesity is associated with low circulating testosterone due to aromatization of testosterone to estrogen by adipose tissue and abnormal hypothalamic-pituitary axis (Haring et al., 2010). Obesity is regarded as an independent risk factor for COVID-19 severity despite low testosterone levels (Yang et al., 2021), although ample evidence from experimental, preclinical, and clinical studies revealed that low testosterone level promotes development of obesity (Fui et al., 2014). Testosterone improves catecholamine-induced lipolysis and inhibits uptake of triglyceride by suppressing the activity of adipose tissue lipoprotein lipase (Grossmann, 2011). It has been reported that patients with prostatic cancer on ADT had increased fat mass and visceral adipose tissue by about $22 \%$ within 6 months of established therapy (Hamilton et al., 2011). Likewise, experimental hypogonadism in young men induces obesity within 10 weeks (Mauras et al., 1998). Therefore, low testosterone-induced obesity may aggravate the clinical course of COVID-19 severity. Sarver and Wong (2021) showed that obesity increases the expression of TMPRSS2 and DPP4 with alteration of the ACE/ACE2 ratio. Thereby, obesity may increase the risk of SARS-CoV-2 infection and abnormal immune response by underlying high pro-inflammatory cytokines (Seidu et al., 2021). Therefore, testosterone's harmful effects in COVID-19 are related to TMPRSS2, ATR1, CD147, DPP4, and 
AngII expression that are mutually interrelated in facilitating SARS-CoV-2 entry and associated inflammatory reactions (Table 2 and Figure 3).

\section{CONCLUSION}

Testosterone hormone has diverse immunological effects; it reduces $\mathrm{B}$ - and $\mathrm{T}$-cell activity with a noteworthy inhibitory effect on macrophage and monocyte activities. Therefore, testosterone has an immunosuppressive effect subjecting male sex for various viral infections including SARS-CoV-2. In the COVID-19 era, different reports, retrospective, and small sample size prospective studies revealed that testosterone serum might correlate with COVID-19 severity and poor clinical outcomes. However, other studies illustrated that testosterone has a protective effect against COVID-19 severity through inhibition of inflammatory signaling pathways including NF- $\mathrm{KB}$, NLRP3

TABLE 2 | Harmful effects of testosterone in COVID-19.

\begin{tabular}{|c|c|c|}
\hline References & Study type & Findings \\
\hline Stopsack et al. (2020) & Systematic review & Testosterone promotes expression of the TMPRSS2. \\
\hline Cao et al. (2017) & Experimental study & Testosterone therapy increases the expression of CD147. \\
\hline Montopoli et al. (2020) & $\begin{array}{l}\text { Population-based } \\
\text { study }\end{array}$ & Androgen deprivation therapy reduces COVID-19 severity. \\
\hline Adamowicz et al. (2020) & Observational study & High dihydrotestosterone level is linked to poor pulmonary outcomes in COVID-19 patients. \\
\hline McCoy et al. (2020) & Observational study & $5-\alpha$ reductase inhibitors is associated with good clinical outcomes in COVID-19 patients. \\
\hline Wambier et al. (2020) & Observational study & Low androgen sensitivity is linked to low COVID-19 mortality. \\
\hline $\begin{array}{l}\text { Wang et al. (2020); Bwire, } \\
\text { (2020) }\end{array}$ & $\begin{array}{l}\text { In vitro and review } \\
\text { studies }\end{array}$ & Circulating testosterone has immunosuppressive effects. \\
\hline Mishra et al. (2019) & Experimental study & $\begin{array}{l}\text { Testosterone has a permissive effect for circulating Angll by expressing AT1R and downregulation of ATR2 with a } \\
\text { higher ATR1R/AT2R ratio. }\end{array}$ \\
\hline Blauschmidt et al. (2017) & Case-series study & Testosterone upregulates the expression of DPP4 receptors. \\
\hline
\end{tabular}

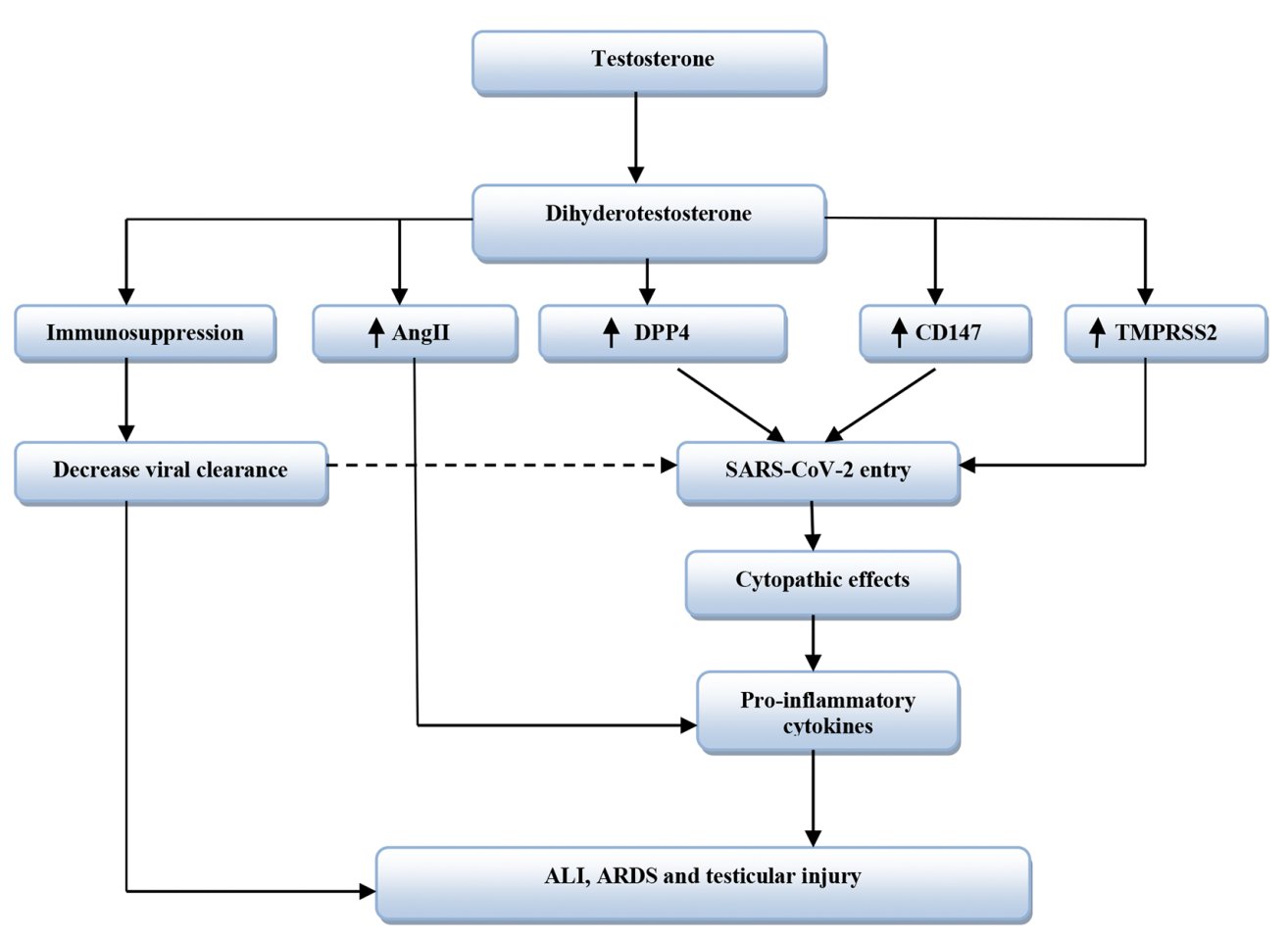

FIGURE 3 | The harmful effects of testosterone in SARS-CoV-2 infection. Dihydrotestosterone from testosterone leads to immunosuppression and increases expression of Dipeptidyl peptidase 4 (DPP4), cluster differentiation 147 (CD147), and Transmembrane protease serine 2 (TMPRSS2). Also, Dihydrotestosterone increases activity of Angiotensin II (Angll). CD147 and DPP4 increase entry of SARS-CoV-2, while TMPRSS2 facilitates SARS-CoV-2 entry. Immunosuppression reduces viral clearance that increases SARS-CoV-2 entry. These changes lead to cytopathic effects with release of pro-inflammatory cytokines with subsequent development of acute lung injury (ALI), acute respiratory distress syndrome (ARDS), and testicular injury. 
inflammasomes, and p38MAPK. Also, testosterone attenuates oxidative stress-induced endothelial dysfunction and associated coagulopathy, a hallmark of COVID-19.

In the present review, depending on the recent published studies, we divided testosterone effects into beneficial and harmful effects. The beneficial effect of testosterone in COVID-19 is mediated through modulation of the pro-inflammatory/antiinflammatory axis with inhibition of SARS-CoV-2-induced oxidative stress. Besides, testosterone attenuates development of ALI and ARDS in SARS-CoV-2 and other respiratory viral infections. The harmful effect of testosterone in COVID-19 is mediated by different unidentified mechanisms, although increased expression of TMPRSS2, DPP4, and CD147 by testosterone might be the potential mechanism. These receptors together with TMPRSS2 facilitate entry of SARS-CoV-2 to the affected cells with subsequent cytopathic effects and release of pro-inflammatory cytokines. Moreover, an increase in androgen sensitivity due to polymorphism of androgenic receptors might be a more important mechanism in the prediction of COVID-19 severity than testosterone serum levels.

On the other hand, a low testosterone serum level in COVID19 patients might be due to direct testicular injury by SARS-CoV-2 or indirectly by the high level of pro-inflammatory cytokines. In addition, SARS-CoV-2-induced oxidative stress may affect testosterone metabolism and action. We suggest that disturbance

\section{REFERENCES}

Abbasi-Oshaghi, E., Mirzaei, F., and Khodadadi, I. (2021). Letter to the Editor Regarding 'COVID-19 and Diabetes: What Does the Clinician Need to Know?'. Prim. Care Diabetes 15 (1), 30. doi: 10.1016/j.pcd.2020.10.010

Abobaker, A., and Raba, A. A. (2020). Does COVID-19 Affect Male Fertility? World J. Urol. 21, 1-2. doi: 10.1007/s00345-020-03208-w

Aboudounya, M. M., and Heads, R. J. (2021). COVID-19 and Toll-Like Receptor 4 (TLR4): SARS-CoV-2 may Bind and Activate TLR4 to Increase ACE2 Expression, Facilitating Entry and Causing Hyperinflammation. Med. Inflamm. 2021, 8874339. doi: 10.1155/2021/8874339

Ackerman, C. M., Lowe, L. P., Lee, H., Hayes, M. G., Dyer, A. R., Metzger, B. E., et al. (2012). Ethnic Variation in Allele Distribution of the Androgen Receptor (AR)(CAG) N Repeat. J. Androl. 33, 210-215. doi: 10.2164/jandrol.111.013391

Adamowicz, J., Juszczak, K., and Drewa, T. (2020). May Patients Receiving 5Alpha-Reductase Inhibitors be in Higher Risk of COVID-19 Complications? Med. Hypotheses 140, 109751. doi: 10.1016/j.mehy.2020.109751

Aitken, R. J. (2020). COVID-19 and Human Spermatozoa-Potential Risks for Infertility and Sexual Transmission? Andrology 9 (1), 48-52. doi: 10.1111/ andr.12859

Al-Kuraishy, H. M., Al-Naimi, M. S., Lungnier, C. M., and Al-Gareeb, A. I. (2020). Macrolides and COVID-19: An Optimum Premise. Biomed. Biotechnol. Res. J. (BBRJ) 4 (3), 189. doi: 10.4103/bbrj.bbrj_103_20

Al-Kuraishy, H. M., Hussien, N. R., Al-Naimi, M. S., Al-Buhadily, A. K., AlGareeb, A. I., and Lungnier, C. (2020a). Is Ivermectin-Azithromycin Combination the Next Step for COVID-19? Biomed. Biotechnol. Res. J. (BBRJ) 4 (5), 101. doi: 10.4103/bbri.bbrj_103_20

Al-Kuraishy, H. M., Hussien, N. R., Al-Naimi, M. S., Al-Buhadily, A. K., AlGareeb, A. I., and Lungnier, C. (2020b). Renin-Angiotensin System and Fibrinolytic Pathway in COVID-19: One-Way Skepticism. Biomed. Biotechnol. Res. J. (BBRJ) 4 (5), 33. doi: 10.4103/bbrj.bbrj_103_20

Al-Maiahy, T. J., Al-Gareeb, A. I., and Al-kuraishy, H. M. (2020). Testosterone Is a Surrogate and Proxy Biomarker for Severity of Late-Onset Preeclampsia: A Cross-Sectional Study. Asian Pacific J. Reprod. 9 (1), 1. doi: 10.4103/23050500.275522 of the hypothalamic-pituitary-gonadal axis by SARS-CoV-2 infection and associated inflammatory disorders could be the possible mechanism for low testosterone in COVID-19.

However, the assorted view of preponderance showed that low testosterone level is linked to COVID-19 severity. In addition, high inflammatory and oxidative stress burden with downregulation of ACE2 in SARS-CoV-2 infection may lead to testicular injury and reduction of testosterone biosynthesis. Despite these findings, the present study cannot conclude the beneficial or harmful effects of testosterone in COVID-19. Clinical trials and large-scale prospective studies are warranted to confirm the potential associations in this regard.

\section{AUTHOR CONTRIBUTIONS}

All authors contributed to the article and approved the submitted version.

\section{FUNDING}

The publication of this study has been supported by the Pnoi Lab - Industrial \& Laboratory Equipment.

Alves, J. V., da Costa, R. M., Pereira, C. A., Fedoce, A. G., Silva, C. A., Carneiro, F S., et al. (2020). Supraphysiological Levels of Testosterone Induce Vascular Dysfunction via Activation of the NLRP3 Inflammasome. Front. Immunol. 11, 1647. doi: 10.3389/fimmu.2020.01647

Anjorin, A. A., Abioye, A. I., Asowata, O. E., Soipe, A., Kazeem, M. I., Adesanya, I. O., et al. (2021). Comorbidities and the COVID-19 Pandemic Dynamics in Africa. Trop. Med. Int. Health 26 (1), 2-13. doi: 10.1111/tmi.13504

Assyov, Y., Gateva, A., Karamfilova, V., Gatev, T., Nedeva, I., Velikova, T., et al. (2020). Impact of Testosterone Treatment on Circulating Irisin in Men With Late-Onset Hypogonadism and Metabolic Syndrome. Aging Male 26, 1-7. doi: $10.1080 / 13685538.2020 .1770721$

Aydilek, N., Aksakal, M., and Karakılçık, A. Z. (2004). Effects of Testosterone and Vitamin E on the Antioxidant System in Rabbit Testis. Andrologia 36 (5), 277 281. doi: 10.1111/j.1439-0272.2004.00618.x

Azimi, A. (2020). TMPRSS2 Inhibitors, Bromhexine, Aprotinin, Camostat and Nafamostat as Potential Treatments for COVID-19. Frenxiv. doi: 10.31226/ osf.io/a3rvm

Baldassarri, M., Picchiotti, N., Fava, F., Fallerini, C., Benetti, E., Daga, S., et al. (2021). Shorter Androgen Receptor polyQ Alleles Protect Against LifeThreatening COVID-19 Disease in European Males. EBioMedicine 65, 103246. doi: 10.1016/j.ebiom.2021.103246

Bank, S., De, S. K., Bankura, B., Maiti, S., Das, M., and Khan, G. A. (2021). ACE/ ACE2 Balance Might be Instrumental to Explain the Certain Comorbidities Lead to Severe COVID-19 Cases. Biosci. Rep. 41 (2), BSR20202014. doi: 10.1042/BSR20202014

Barnes, M. J., Li, C. M., Xu, Y., An, J., Huang, Y., and Cyster, J. G. (2015). The Lysophosphatidylserine Receptor GPR174 Constrains Regulatory T Cell Development and Function. J. Exp. Med. 212 (7), 1011-1020. doi: 10.1084/jem.20141827

Becerra-Díaz, M., Strickland, A. B., Keselman, A., and Heller, N. M. (2018). Androgen and Androgen Receptor as Enhancers of M2 Macrophage Polarization in Allergic Lung Inflammation. J. Immunol. 201 (10), 2923 2933. doi: 10.4049/jimmunol.1800352

Bech, A., van Leeuwen, H., Telting, D., van Borren, M., and de Boer, H. (2020). Time Course of Gonadal Hormone Profiles in Male Patients With Sepsis. Age (Years) 72, 43-84. 
Bennink, H. J., Foidart, J. M., and Debruyne, F. M. (2021). Treatment of Serious COVID-19 With Testosterone Suppression and High-Dose Estrogen Therapy. Eur. Urol. 6, S0302-2838(21)01865-0. doi: 10.1016/j.eururo.2021.06.024.

Bereshchenko, O., Bruscoli, S., and Riccardi, C. (2018). Glucocorticoids, Sex Hormones, and Immunity. Front. Immunol. 9, 1332. doi: 10.3389/ fimmu.2018.01332

Bianchi, V. E. (2019). The Anti-Inflammatory Effects of Testosterone. J. Endocr. Soc. 3 (1), 91-107. doi: 10.1210/js.2018-00186

Blauschmidt, S., Greither, T., Lampe, K., Köller, S., Kaltwaßer, P., and Behre, H. M. (2017). Dipeptidyl Peptidase 4 Serum Activity and Concentration Are Increased in Women With Polycystic Ovary Syndrome. Clin. Endocrinol. 87 (6), 741-747. doi: 10.1111/cen.13444

Breining, P., Frølund, A. L., Højen, J. F., Gunst, J. D., Staerke, N. B., Saedder, E, et al. (2020). Camostat Mesylate Against SARS-CoV-2 and COVID-19Rationale, Dosing and Safety. Basic Clin. Pharmacol. Toxicol. 128 (2), 204212. doi: 10.1111/bcpt.13533.

Bukowska, A., Spiller, L., Wolke, C., Lendeckel, U., Weinert, S., Hoffmann, J., et al. (2017). Protective Regulation of the ACE2/ACE Gene Expression by Estrogen in Human Atrial Tissue From Elderly Men. Exp. Biol. Med. 242 (14), 14121423. doi: $10.1177 / 1535370217718808$

Butanis, J., Beckett, E., and Kabadi, U. M. (2017). Male Hypogonadism. Primary Care Rep. 23 (1), 23-29. doi: 10.1097/01.NPR.0000511774.51873.da

Bwire, G. M. (2020). Coronavirus: Why Men Are More Vulnerable to Covid-19 Than Women? SN Compr. Clin. Med. 2 (7), 874-876. doi: 10.1007/s42399-020-00341-w

Callewaert, L., Christiaens, V., Haelens, A., Verrijdt, G., Verhoeven, G., and Claessens, F. (2003). Implications of a Polyglutamine Tract in the Function of the Human Androgen Receptor. Biochem. Biophys. Res. Commun. 306 (1), 4652. doi: 10.1016/S0006-291X(03)00902-1

Cao, J., Ng, M., and Felmlee, M. A. (2017). Sex Hormones Regulate Rat Hepatic Monocarboxylate Transporter Expression and Membrane Trafficking. J. Pharm. Pharm. Sci. 20, 435-444. doi: 10.18433/J3CH29

Çayan, S., Uğuz, M., Saylam, B., and Akbay, E. (2020). Effect of Serum Total Testosterone and Its Relationship With Other Laboratory Parameters on the Prognosis of Coronavirus Disease 2019 (COVID-19) in SARS-CoV-2 Infected Male Patients: A Cohort Study. Aging Male 23 (5), 1493-1503. doi: 10.1080/ 13685538.2020.1807930

Cheng, Z., Zhou, J., To, K. K., Chu, H., Li, C., Wang, D., et al. (2015). Identification of TMPRSS2 as a Susceptibility Gene for Severe 2009 Pandemic A (H1N1) Influenza and A (H7N9) Influenza. J. Infect. Dis. 212 (8), 1214-1221. doi: 10.1093/infdis/jiv246

Chen, S., Markman, J. L., Shimada, K., Crother, T. R., Lane, M., Abolhesn, A., et al. (2020). Sex-Specific Effects of the Nlrp3 Inflammasome on Atherogenesis in LDL Receptor-Deficient Mice. Basic Trans. Sci. 5 (6), 582-598. doi: 10.1016/ j.jacbts.2020.03.016

Chen, Y., Wang, J., Chen, X., Li, D., and Han, X. (2018). Microcystin-Leucine Arginine Mediates Apoptosis and Engulfment of Leydig Cell by Testicular Macrophages Resulting in Reduced Serum Testosterone Levels. Aquat. Toxicol. 199, 116-126. doi: 10.1016/j.aquatox.2018.03.018

Chi, M., Shi, X., Huo, X., Wu, X., Zhang, P., and Wang, G. (2020). Dexmedetomidine Promotes Breast Cancer Cell Migration Through Rab11Mediated Secretion of Exosomal TMPRSS2. Ann. Trans. Med. 8 (8), 531. doi: 10.21037/atm.2020.04.28

Ciarambino, T., Barbagelata, E., Corbi, G., Ambrosino, I., Politi, C., Lavalle, F., et al. (2021). Gender Differences in Vaccine Therapy: Where Are We in COVID-19 Pandemic? Monaldi Arch. Chest Dis. 8. doi: 10.4081/monaldi.2021.1669

Cinislioglu, A. E., Cinislioglu, N., Demirdogen, S. O., Sam, E., Akkas, F., Altay, M. S., et al. (2021). The Relationship of Serum Testosterone Levels With the Clinical Course and Prognosis of COVID-19 Disease in Male Patients: A Prospective Study. Andrology. doi: 10.1111/andr.13081

Cronauer, M. V., Ince, Y., Engers, R., Rinnab, L., Weidemann, W., Suschek, C. V., et al. (2007). Nitric Oxide-Mediated Inhibition of Androgen Receptor Activity: Possible Implications for Prostate Cancer Progression. Oncogene 26 (13), 1875-1884. doi: 10.1038/sj.onc.1209984

de Lusignan, S., Dorward, J., Correa, A., Jones, N., Akinyemi, O., Amirthalingam, G., et al. (2020). Risk Factors for SARS-CoV-2 Among Patients in the Oxford Royal College of General Practitioners Research and Surveillance Centre
Primary Care Network: A Cross-Sectional Study. Lancet Infect. Dis. 20 (9), 1034-1042. doi: 10.1016/S1473-3099(20)30371-6

Donlan, A. N., Young, M., Petri, W. A., and Abhyankar, M. (2020). IL-13 Predicts the Need for Mechanical Ventilation in COVID-19 Patients. medRxiv 1, 202006. doi: $10.1101 / 2020.06 .18 .20134353$

Duarte-Neto, A. N., Teixeira, T. A., Caldini, E. G., Kanamura, C. T., GomesGouvêa, M. S., Dos Santos, A. B., et al. (2021). Testicular Pathology in Fatal COVID-19: A Descriptive Autopsy Study. Andrology 28 (1), 23-26. doi: 10.1111/andr.13073

Dutta, S., and Sengupta, P. (2021). SARS-CoV-2 and Male Infertility: Possible Multifaceted Pathology. Reprod. Sci. 28 (1), 23-26. doi: 10.1007/s43032-02000261-z

Esteves, S. C., Lombardo, F., Garrido, N., Alvarez, J., Zini, A., Colpi, G. M., et al. (2021). SARS-CoV-2 Pandemic and Repercussions for Male Infertility Patients: A Proposal for the Individualized Provision of Andrological Services. Andrology 9 (1), 10-18. doi: 10.1111/andr.12809

Evens, L., Beliën, H., Deluyker, D., Bronckaers, A., Gervois, P., Hendrikx, M., et al. (2020). The Impact of Advanced Glycation End-Products (AGEs) on Proliferation and Apoptosis of Primary Stem Cells: A Systematic Review. Stem Cells Int. 14 (2020), 8886612. doi: 10.1155/2020/8886612

Farghaly, S., and Makboul, M. (2021). Correlation Between Age, Sex, and Severity of Coronavirus Disease-19 Based on Chest Computed Tomography Severity Scoring System. Egyptian J. Radiol. Nucl. Med. 52 (1), 1-8. doi: 10.1186/ s43055-021-00408-1

Farsalinos, K., Niaura, R., Le Houezec, J., Barbouni, A., Tsatsakis, A., Kouretas, D., et al. (2020). Nicotine and SARS-CoV-2: COVID-19 may be a Disease of the Nicotinic Cholinergic System. Toxicol. Rep. 7, 658. doi: 10.1016/ j.toxrep.2020.04.012

Fei, Y., Tang, N., Liu, H., and Cao, W. (2020). Coagulation Dysfunction: A Hallmark in COVID-19. Arch. Pathol. Lab. Med. 144 (10), 1223-1229. doi: 10.5858/arpa.2020-0324-SA

Flaifel, A., Guzzetta, M., Occidental, M., Najari, B. B., Melamed, J., Thomas, K. M., et al. (2021). Testicular Changes Associated With Severe Acute Respiratory Syndrome Coronavirus 2 (SARS-CoV-2). Arch. Pathol. Lab. Med. 145 (1), 8-9. doi: 10.5858/arpa.2020-0487-LE

Fui, M. N., Dupuis, P., and Grossmann, M. (2014). Lowered Testosterone in Male Obesity: Mechanisms, Morbidity and Management. Asian J. Androl. 16 (2), 223.

Ghosh, S., and Klein, R. S. (2017). Sex Drives Dimorphic Immune Responses to Viral Infections. J. Immunol. 198 (5), 1782-1790. doi: 10.4049/jimmunol.1601166

Giagulli, V. A., Guastamacchia, E., Magrone, T., Jirillo, E., Lisco, G., De Pergola, G., et al. (2021). Worse Progression of COVID-19 in Men: Is Testosterone a Key Factor? Andrology 9 (1), 53-64. doi: 10.1111/andr.12836

Goren, A., Vaño-Galván, S., Wambier, C. G., McCoy, J., Gomez-Zubiaur, A., Moreno-Arrones, O. M., et al. (2020). A Preliminary Observation: Male Pattern Hair Loss Among Hospitalized COVID-19 Patients in Spain-A Potential Clue to the Role of Androgens in COVID-19 Severity. J. Cosmetic Dermatol. 19 (7), 1545-1547. doi: 10.1111/jocd.13443

Grimes, J. M., and Grimes, K. V. (2020). P38 MAPK Inhibition: A Promising Therapeutic Approach for COVID-19. J. Mol. Cell. Cardiol. 144, 63-65. doi: 10.1016/j.yjmcc.2020.05.007

Grossmann, M. (2011). Low Testosterone in Men With Type 2 Diabetes: Significance and Treatment. J. Clin. Endocrinol. Metab. 96 (8), 2341-2353. doi: 10.1210/jc.2011-0118

Grossmann, M., Ng Tang Fui, M., and Cheung, A. S. (2020). Late-Onset Hypogonadism: Metabolic Impact. Andrology 8 (6), 1519-1529. doi: 10.1111/andr.12705

Gubbels Bupp, M. R., and Jorgensen, T. N. (2018). Androgen-Induced Immunosuppression. Front. Immunol. 9, 794. doi: 10.3389/fimmu.2018.00794

Guo, J., Ma, K., Xia, H. M., Chen, Q. K., Li, L., Deng, J., et al. (2018). Androgen Receptor Reverts Dexamethasone Induced Inhibition of Prostate Cancer Cell Proliferation and Migration. Mol. Med. Rep. 17 (4), 5887-5893. doi: 10.3892/ mmr.2018.8566

Hamilton, E. J., Gianatti, E., Strauss, B. J., Wentworth, J., Lim-Joon, D., Bolton, D., et al. (2011). Increase in Visceral and Subcutaneous Abdominal Fat in Men With Prostate Cancer Treated With Androgen Deprivation Therapy. Clin. Endocrinol. 74 (3), 377-383. doi: 10.1111/j.1365-2265.2010.03942.x 
Handelsman, D. J., Hirschberg, A. L., and Bermon, S. (2018). Circulating Testosterone as the Hormonal Basis of Sex Differences in Athletic Performance. Endocrine Rev. 39 (5), 803-829. doi: 10.1210/er.2018-00020

Han, A., Zou, L., Gan, X., Li, Y., Liu, F., Chang, X., et al. (2018). ROS Generation and MAPKs Activation Contribute to the Ni-Induced Testosterone Synthesis Disturbance in Rat Leydig Cells. Toxicol. Lett. 290, 36-45. doi: 10.1016/ j.toxlet.2018.03.016

Haring, R., Ittermann, T., Völzke, H., Krebs, A., Zygmunt, M., Felix, S. B., et al. (2010). Prevalence, Incidence and Risk Factors of Testosterone Deficiency in a Population-Based Cohort of Men: Results From the Study of Health in Pomerania. Aging Male 13 (4), 247-257. doi: 10.3109/13685538.2010.487553

Hotta, Y., Kataoka, T., and Kimura, K. (2019). Testosterone Deficiency and Endothelial Dysfunction: Nitric Oxide, Asymmetric Dimethylarginine, and Endothelial Progenitor Cells. Sexual Med. Rev. 7 (4), 661-668. doi: 10.1016/ j.sxmr.2019.02.005

Illiano, E., Trama, F., and Costantini, E. (2020). Could COVID-19 Have an Impact on Male Fertility? Andrologia 52 (6), e13654. doi: 10.1111/and.13654

Jardí, F., Laurent, M. R., Claessens, F., and Vanderschueren, D. (2018). Estradiol and Age-Related Bone Loss in Men. Physiol. Rev. 98 (1), 1-. doi: 10.1152/ physrev.00051.2017

Jing, J., Ding, N., Wang, D., Ge, X., Ma, J., Ma, R., et al. (2020). Oxidized-LDL Inhibits Testosterone Biosynthesis by Affecting Mitochondrial Function and the P38 MAPK/COX-2 Signaling Pathway in Leydig Cells. Cell Death Dis. 11 (8), 1-5. doi: 10.1038/s41419-020-02751-z

Keilich, S. R., Bartley, J. M., and Haynes, L. (2019). Diminished Immune Responses With Aging Predispose Older Adults to Common and Uncommon Influenza Complications. Cell. Immunol. 345, 103992. doi: 10.1016/j.cellimm.2019.103992

Kikkert, M. (2020). Innate Immune Evasion by Human Respiratory RNA Viruses. J. Innate Immun. 12 (1), 4-20. doi: 10.1159/000503030

Kissick, H. T., Sanda, M. G., Dunn, L. K., Pellegrini, K. L., On, S. T., Noel, J. K., et al. (2014). Androgens Alter T-Cell Immunity by Inhibiting T-Helper 1 Differentiation. Proc. Natl. Acad. Sci. 111 (27), 9887-9892. doi: 10.1073/ pnas. 1402468111

Laforge, M., Elbim, C., Frère, C., Hémadi, M., Massaad, C., Nuss, P., et al. (2020). Tissue Damage From Neutrophil-Induced Oxidative Stress in COVID-19. Nat. Rev. Immunol. 20 (9), 515-516. doi: 10.1038/s41577-020-0407-1

LaVere, A. A., Hamlin, H. J., Lowers, R. H., Parrott, B. B., and Ezenwa, V. O. (2021). Associations Between Testosterone and Immune Activity in Alligators Depend on Bacteria Species and Temperature. Funct. Ecol. 35 (5), 1018-1027. doi: $10.1111 / 1365-2435.13756$

Lipsky, M. S., and Hung, M. (2020). Men and COVID-19: A Pathophysiologic Review. Am. J. Men's Health 14 (5), 1557988320954021. doi: 10.1177/ 1557988320954021

Liu, J., Ren, L., Wei, J., Zhang, J., Zhu, Y., Li, X., et al. (2018). Fine Particle Matter Disrupts the Blood-Testis Barrier by Activating TGF- $\beta 3 /$ P38 MAPK Pathway and Decreasing Testosterone Secretion in Rat. Environ. Toxicol. 33 (7), 711719. doi: $10.1002 /$ tox. 22556

Lugnier, C., AL-Kuraishi, H. M., and Rousseau, E. (2021). PDE4 Inhibition as a Therapeutic Strategy for Improvement of Pulmonary Dysfunctions in Covid19 and Cigarette Smoking. Biochem. Pharmacol. 28, 114431. doi: 10.1016/ j.bcp.2021.114431

Lv, J., Wang, Z., Qu, Y., Zhu, H., Zhu, Q., Tong, W., et al. (2021). Distinct Uptake, Amplification, and Release of SARS-CoV-2 by M1 and M2 Alveolar Macrophages. Cell Discov. 7 (1), 1-2. doi: 10.1038/s41421-021-00258-1

Maddaloni, E., D'Onofrio, L., Alessandri, F., Mignogna, C., Leto, G., Pascarella, G., et al. (2020). Cardiometabolic Multimorbidity Is Associated With a Worse Covid-19 Prognosis Than Individual Cardiometabolic Risk Factors: A Multicentre Retrospective Study (CoViDiab II). Cardiovasc. Diabetol. 19 (1), 1-1. doi: 10.1186/s12933-020-01140-2

Ma, Q., Hao, Z. W., and Wang, Y. F. (2021). The Effect of Estrogen in Coronavirus Disease 2019 (COVID-19). Am. J. Physiol-Lung Cell. Mol. Physiol. 321 (1), L219-L227. doi: 10.1152/ajplung.00332.2020

Marin, D. P., Bolin, A. P., de Cassia Macedo dos Santos, R., Curi, R., and Otton, R. (2010). Testosterone Suppresses Oxidative Stress in Human Neutrophils. Cell Biochem. Funct. 28 (5), 394-402. doi: 10.1002/cbf.1669

Marques, D. A., Patrone, L. G., Scarpellini, C. S., Bícego, K. C., Szawka, R. E., and Gargaglioni, L. H. (2020). The Role of Testosterone in the Respiratory and
Thermal Responses to Hypoxia and Hypercapnia in Rats. J. Endocrinol. 247 (1), 101-114. doi: 10.1530/JOE-20-0257

Martin, L. J., and Touaibia, M. (2020). Improvement of Testicular Steroidogenesis Using Flavonoids and Isoflavonoids for Prevention of Late-Onset Male Hypogonadism. Antioxidants 9 (3), 237. doi: 10.3390/antiox9030237

Mauras, N., Hayes, V., Welch, S., Rini, A., Helgeson, K., Dokler, M., et al. (1998). Testosterone Deficiency in Young Men: Marked Alterations in Whole Body Protein Kinetics, Strength, and Adiposity. J. Clin. Endocrinol. Metab. 83 (6), 1886-1892. doi: 10.1210/jc.83.6.1886

McCoy, J., Cadegiani, F. A., Wambier, C. G., Herrera, S., Vaño-Galván, S., Mesinkovska, N. A., et al. (2020). 5-Alpha-Reductase Inhibitors Are Associated With Reduced Frequency of COVID-19 Symptoms in Males With Androgenetic Alopecia. J. Eur. Acad. Dermatol. Venereol. 35 (4), e243e246. doi: $10.1111 /$ jdv.17021

McGonagle, D., Ramanan, A. V., and Bridgewood, C. (2021). Immune Cartography of Macrophage Activation Syndrome in the COVID-19 Era. Nat. Rev. Rheumatol. 17 (3), 145-157. doi: 10.1038/s41584-020-00571-1

Mehra, R., Tomlins, S. A., Shen, R., Nadeem, O., Wang, L., Wei, J. T., et al. (2007). Comprehensive Assessment of TMPRSS2 and ETS Family Gene Aberrations in Clinically Localized Prostate Cancer. Modern Pathol. 20 (5), 538-544. doi: 10.1038/modpathol.3800769

Meinhardt, A., Wang, M., Schulz, C., and Bhushan, S. (2018). Microenvironmental Signals Govern the Cellular Identity of Testicular Macrophages. J. Leukocyte Biol. 104 (4), 757-766. doi: 10.1002/JLB.3MR0318-086RR

Messina, G., Polito, R., Monda, V., Cipolloni, L., Di Nunno, N., Di Mizio, G., et al. (2020). Functional Role of Dietary Intervention to Improve the Outcome of COVID-19: A Hypothesis of Work. Int. J. Mol. Sci. 21 (9), 3104. doi: 10.3390/ ijms 21093104

Millar, A. C., Lau, A. N., Tomlinson, G., Kraguljac, A., Simel, D. L., Detsky, A. S., et al. (2016). Predicting Low Testosterone in Aging Men: A Systematic Review. CMAJ 188 (13), E321-E330. doi: 10.1503/cmaj.150262

Mirani, M., Favacchio, G., Carrone, F., Betella, N., Biamonte, E., Morenghi, E., et al. (2020). Impact of Comorbidities and Glycemia at Admission and Dipeptidyl Peptidase 4 Inhibitors in Patients With Type 2 Diabetes With COVID-19: A Case Series From an Academic Hospital in Lombardy, Italy. Diabetes Care 43 (12), 3042-3049. doi: 10.2337/dc20-1340

Mishra, J. S., More, A. S., Gopalakrishnan, K., and Kumar, S. (2019). Testosterone Plays a Permissive Role in Angiotensin II-Induced Hypertension and Cardiac Hypertrophy in Male Rats. Biol. Reprod. 100 (1), 139-148. doi: 10.1093/biolre/ioy179

Mohamad, N. V., Wong, S. K., Hasan, W. N., Jolly, J. J., Nur-Farhana, M. F., ImaNirwana, S., et al. (2018). The Relationship Between Circulating Testosterone and Inflammatory Cytokines in Men. Aging Male 22 (2), 129-140. doi: $10.1080 / 13685538.2018 .1482487$

Montano, L. M., Espinoza, J., Flores-Soto, E., Chávez, J., and Perusquia, M. (2014). Androgens Are Bronchoactive Drugs That Act by Relaxing Airway Smooth Muscle and Preventing Bronchospasm. J. Endocrinol. 1222 (1), 1-3. doi: 10.1530/JOE-14-0074

Montopoli, M., Zumerle, S., Vettor, R., Rugge, M., Zorzi, M., Catapano, C. V., et al. (2020). Androgen-Deprivation Therapies for Prostate Cancer and Risk of Infection by SARS-CoV-2: A Population-Based Study $(\mathrm{N}=4532)$. Ann. Oncol. 31 (8), 1040-1045. doi: 10.1016/j.annonc.2020.04.479

Mukherjee, S., and Pahan, K. (2021). Is COVID-19 Gender-Sensitive? J. Neuroimmune Pharmacol. 16 (1), 38-47. doi: 10.1007/s11481-020-09974-z.

Novković, L., Lazić, Z., Petrović, M., Cupurdija, V., Vujanac, K., and Čekerevac, I. (2019). Hypogonadism in Chronic Obstructive Pulmonary Disease (COPD): Risk Factors. Vojnosanitetski Pregled 76 (1), 55-60. doi: 10.2298/ VSP170312081N

Ntyonga-Pono, M. P. (2020). COVID-19 Infection and Oxidative Stress: An Under-Explored Approach for Prevention and Treatment? Pan Afr. Med. J. 35 (Suppl 2), 12. doi: 10.11604/pamj.2020.35.2.22877

Okçelik, S. (2021). COVID-19 Pneumonia Causes Lower Testosterone Levels. Andrologia 53 (1), e13909. doi: 10.1111/and.13909

Ong, S. W., Tan, W. Y., Chan, Y. H., Fong, S. W., Renia, L., Ng, L. F., et al. (2020). Safety and Potential Efficacy of Cyclooxygenase-2 Inhibitors in Coronavirus Disease 2019. Clin. Trans. Immunol. 9 (7), e1159. doi: 10.1002/cti2.1159

Papadopoulos, V., Li, L., and Samplaski, M. (2020). Why Does COVID-19 Kill More Elderly Men Than Women? Is There a Role for Testosterone? Andrology 22 (2), 129-140. doi: 10.1080/13685538.2018.1482487 
Papadopoulos, V., Li, L., and Samplaski, M. (2021). Why Does COVID-19 Kill More Elderly Men Than Women? Is There a Role for Testosterone? Andrology 9 (1), 65-72. doi: $10.1111 /$ andr.12868

Pascolo, L., Zito, G., Zupin, L., Luppi, S., Giolo, E., Martinelli, M., et al. (2020). Renin Angiotensin System, COVID-19 and Male Fertility: Any Risk for Conceiving? Microorganisms 8 (10), 1492. doi: 10.3390/microorganisms 8101492

Pereira, M. R., Mohan, S., Cohen, D. J., Husain, S. A., Dube, G. K., Ratner, L. E., et al. (2020). COVID-19 in Solid Organ Transplant Recipients: Initial Report From the US Epicenter. Am. J. Transplant. 20 (7), 1800-1808. doi: 10.1111/ ajt.15941

Pezzaioli, L. C., Quiros-Roldan, E., Paghera, S., Porcelli, T., Maffezzoni, F., Delbarba, A., et al. (2020). The Importance of SHBG and Calculated Free Testosterone for the Diagnosis of Symptomatic Hypogonadism in HIVInfected Men: A Single-Centre Real-Life Experience. Infection 49 (2), 295303. doi: 10.1007/s15010-020-01558-6

Pierotti, S., Lolli, F., Lauretta, R., Graziadio, C., Di Dato, C., Sbardella, E., et al. (2010). Androgen Modulation of Pro-Inflammatory and Anti-Inflammatory Cytokines During Preadipocyte Differentiation. Horm. Mol. Biol. Clin. Invest. 4 (1), 483-488. doi: 10.1515/HMBCI.2010.059

Piva, F., Sabanovic, B., Cecati, M., and Giulietti, M. (2021). Expression and CoExpression Analyses of TMPRSS2, a Key Element in COVID-19. Eur. J. Clin. Microbiol. Infect. Dis. 40 (2), 451-455. doi: 10.1007/s10096-020-04089-y

Priyanka, H. P., and Nair, R. S. (2020). Neuroimmunomodulation by Estrogen in Health and Disease. AIMS Neurosci. 7 (4), 401. doi: 10.3934/ Neuroscience.2020025

Qiu, D., Chu, X., Hua, L., Yang, Y., Li, K., Han, Y., et al. (2019). Gpr174-Deficient Regulatory T Cells Decrease Cytokine Storm in Septic Mice. Cell Death Dis. 10 (3), 1-4. doi: 10.1038/s41419-019-1462-z

Radzikowska, U., Ding, M., Tan, G., Zhakparov, D., Peng, Y., Wawrzyniak, P., et al. (2020). Distribution of ACE2, CD147, CD26, and Other SARS-CoV-2 Associated Molecules in Tissues and Immune Cells in Health and in Asthma, COPD, Obesity, Hypertension, and COVID-19 Risk Factors. Allergy 75 (11), 2829-2845. doi: 10.1111/all.14429

Rahman, N., Basharat, Z., Yousuf, M., Castaldo, G., Rastrelli, L., and Khan, H. (2020). Virtual Screening of Natural Products Against Type II Transmembrane Serine Protease (TMPRSS2), the Priming Agent of Coronavirus 2 (SARS-CoV2). Molecules 25 (10), 2271. doi: 10.3390/molecules 25102271

Rastrelli, G., Di Stasi, V., Inglese, F., Beccaria, M., Garuti, M., Di Costanzo, D., et al. (2020). Low Testosterone Levels Predict Clinical Adverse Outcomes in SARSCoV-2 Pneumonia Patients. Andrology 9 (1), 88-98. doi: 10.1111/andr.12821

Redente, E. F., Jacobsen, K. M., Solomon, J. J., Lara, A. R., Faubel, S., Keith, R. C., et al. (2011). Age and Sex Dimorphisms Contribute to the Severity of Bleomycin-Induced Lung Injury and Fibrosis. Am. J. Physiol-Lung Cell. Mol. Physiol. 301 (4), L510-L518. doi: 10.1152/ajplung.00122.2011

Reis, F. M., and Reis, A. M. (2020). Angiotensin-Converting Enzyme 2 (ACE2), Angiotensin-(1-7) and Mas Receptor in Gonadal and Reproductive Functions. Clin. Sci. 134 (22), 2929-2941. doi: 10.1042/CS20200865

Rettew, J. A., Huet-Hudson, Y. M., and Marriott, I. (2008). Testosterone Reduces Macrophage Expression in the Mouse of Toll-Like Receptor 4, A Trigger for Inflammation and Innate Immunity. Biol. Reprod. 78 (3), 432-437. doi: 10.1095/biolreprod.107.063545

Roved, J., Westerdahl, H., and Hasselquist, D. (2017). Sex Differences in Immune Responses: Hormonal Effects, Antagonistic Selection, and Evolutionary Consequences. Horm. Behav. 88, 95-105. doi: 10.1016/j.yhbeh.2016.11.017

Salonia, A., Corona, G., Giwercman, A., Maggi, M., Minhas, S., Nappi, R. E., et al. (2021). SARS-CoV-2, Testosterone and Frailty in Males (PROTEGGIMI): A Multidimensional Research Project. Andrology 9 (1), 19-22. doi: 10.1111/ andr.12811

Sarver, D. C., and Wong, G. W. (2021). Obesity Alters Ace2 and Tmprss2 Expression in Lung, Trachea, and Esophagus in a Sex-Dependent Manner: Implications for COVID-19. Biochem. Biophys. Res. Commun. 538, 92-96. doi: 10.1016/j.bbrc.2020.10.066

Schönrich, G., Raftery, M. J., and Samstag, Y. (2020). Devilishly Radical NETwork in COVID-19: Oxidative Stress, Neutrophil Extracellular Traps (NETs), and T Cell Suppression. Adv. Biol. Regul. 77, 100741. doi: 10.1016/ j.jbior.2020.100741
Schroeder, M., Tuku, B., Jarczak, D., Nierhaus, A., Bai, T., Jacobsen, H., et al. (2020). The Majority of Male Patients With COVID-19 Present Low Testosterone Levels on Admission to Intensive Care in Hamburg, Germany: A Retrospective Cohort Study. medRxiv. doi: 10.1101/2020.05.07.20073817

Seidu, S., Gillies, C., Zaccardi, F., Kunutsor, S. K., Hartmann-Boyce, J., Yates, T., et al. (2021). The Impact of Obesity on Severe Disease and Mortality in People With SARS-CoV-2: A Systematic Review and Meta-Analysis. Endocrinol. Diabetes Metab. 4 (1), e00176. doi: 10.1002/edm2.176

Serveaux-Dancer, M., Jabaudon, M., Creveaux, I., Belville, C., Blondonnet, R., Gross, C., et al. (2019). Pathological Implications of Receptor for Advanced Glycation End-Product (AGER) Gene Polymorphism. Dis. Markers 2019, 2067353. doi: 10.1155/2019/2067353

Shen, L. W., Qian, M. Q., Yu, K., Narva, S., Yu, F., Wu, Y. L., et al. (2020). Inhibition of Influenza A Virus Propagation by Benzoselenoxanthenes Stabilizing TMPRSS2 Gene G-Quadruplex and Hence Down-Regulating TMPRSS2 Expression. Sci. Rep. 10 (1), 1-2. doi: 10.1038/s41598-020-64368-8

Shi, T., and Dansen, T. B. (2020). Reactive Oxygen Species Induced P53 Activation: DNA Damage, Redox Signaling, or Both? Antioxid. Redox Signal. 33 (12), 839-859. doi: 10.1089/ars.2020.8074

Solerte, S. B., Di Sabatino, A., Galli, M., and Fiorina, P. (2020). Dipeptidyl Peptidase-4 (DPP4) Inhibition in COVID-19. Acta Diabetol. 57, 779-783. doi: 10.1007/s00592-020-01539-z

Stopsack, K. H., Mucci, L. A., Antonarakis, E. S., Nelson, P. S., and Kantoff, P. W. (2020). TMPRSS2 and COVID-19: Serendipity or Opportunity for Intervention? Cancer Discov. 10 (6), 779-782. doi: 10.1158/2159-8290.CD20-0451

Suba, Z. (2020). Prevention and Therapy of COVID-19 via Exogenous Estrogen Treatment for Both Male and Female Patients: Prevention and Therapy of COVID-19. J. Pharm. Pharm. Sci. 23, 75-85. doi: 10.18433/jpps31069

Sun, X., Wang, T., Cai, D., Hu, Z., Liao, H., Zhi, L., et al. (2020). Cytokine Storm Intervention in the Early Stages of COVID-19 Pneumonia. Cytokine Growth Factor Rev. 53, 38-42. doi: 10.1016/j.cytogfr.2020.04.002

Trigunaite, A., Dimo, J., and Jørgensen, T. N. (2015). Suppressive Effects of Androgens on the Immune System. Cell. Immunol. 294 (2), 87-94. doi: 10.1016/j.cellimm.2015.02.004

van den Berg, D. F., and Te Velde, A. A. (2020). Severe COVID-19: NLRP3 Inflammasome Dysregulated. Front. Immunol. 11, 1580. doi: 10.3389/ fimmu.2020.01580

Vignozzi, L., Cellai, I., Santi, R., Lombardelli, L., Morelli, A., Comeglio, P., et al. (2012). Antiinflammatory Effect of Androgen Receptor Activation in Human Benign Prostatic Hyperplasia Cells. J. Endocrinol. 214 (1), 31. doi: 10.1530/ JOE-12-0142.

Voinsky, I., and Gurwitz, D. (2020). Smoking and COVID-19: Similar Bronchial ACE2 and TMPRSS2 Expression and Higher TMPRSS4 Expression in Current Versus Never Smokers. Drug Dev. Res. 81 (8), 1073-1080. doi: 10.1002/ ddr.21729

Wambier, C. G., Goren, A., Vaño-Galván, S., Ramos, P. M., Ossimetha, A., Nau, G., et al. (2020). Androgen Sensitivity Gateway to COVID-19 Disease Severity. Drug Dev. Res. 81 (7), 771-776. doi: 10.1002/ddr.21688

Wang, X., Huang, L., Jiang, S., Cheng, K., Wang, D., Luo, Q., et al. (2021). Testosterone Attenuates Pulmonary Epithelial Inflammation in Male Rats of COPD Model Through Preventing NRF1-Derived NF-kb Signaling. J. Mol. Cell Biol. 13 (2), 128-140. doi: 10.1093/jmcb/mjaa079

Wang, F., Nie, J., Wang, H., Zhao, Q., Xiong, Y., Deng, L., et al. (2020). Characteristics of Peripheral Lymphocyte Subset Alteration in COVID-19 Pneumonia. J. Infect. Dis. 221 (11), 1762-1769. doi: 10.1093/infdis/jiaa150

Wang, H., Wang, T., Yuan, Z., Cao, Y., Zhou, Y., He, J., et al. (2018). Role of Receptor for Advanced Glycation End Products in Regulating Lung Fluid Balance in Lipopolysaccharide-Induced Acute Lung Injury and InfectionRelated Acute Respiratory Distress Syndrome. Shock 50 (4), 472-482. doi: 10.1097/SHK.0000000000001032

Wang, Y., Wu, H., Xin, Y., Bai, Y., Kong, L., Tan, Y., et al. (2017). Sulforaphane Prevents Angiotensin II-Induced Testicular Cell Death via Activation of NRF2. Oxid. Med. Cell. Longev. 2017, 5374897. doi: 10.1155/2017/5374897

Wu, Z., Hu, R., Zhang, C., Ren, W., Yu, A., and Zhou, X. (2020). Elevation of Plasma Angiotensin II Level Is a Potential Pathogenesis for the Critically Ill COVID-19 Patients. Crit. Care 24, 1-3. doi: 10.1186/s13054-020-03015-0 
Xu, H., Wang, Z., Feng, C., Yu, W., Chen, Y., Zeng, X., et al. (2021). Effects of SARS-CoV-2 Infection on Male Sex-Related Hormones in Recovering Patients. Andrology 9 (1), 107-114. doi: 10.1111/andr.12942

Yalcin Kehribar, D., Cihangiroglu, M., Sehmen, E., Avci, B., Capraz, A., Yildirim Bilgin, A., et al. (2020). The Receptor for Advanced Glycation End Product (RAGE) Pathway in COVID-19. Biomarkers 7, 1-7. doi: 10.1080/ 1354750X.2020.1861099

Yang, M., Chen, S., Huang, B., Zhong, J. M., Su, H., Chen, Y. J., et al. (2020). Pathological Findings in the Testes of COVID-19 Patients: Clinical Implications. Eur. Urol. Focus 6 (5), 1124-1129. doi: 10.1016/j.euf.2020.05.009

Yang, J., Hu, J., and Zhu, C. (2021). Obesity Aggravates COVID-19: A Systematic Review and Meta-Analysis. J. Med. Virol. 93 (1), 257-261. doi: 10.1002/ jimv.26237

Zaim, S., Chong, J. H., Sankaranarayanan, V., and Harky, A. (2020). COVID-19 and Multi-Organ Response. Curr. Problems Cardiol. 28, 100618. doi: 10.1016/ j.cpcardiol.2020.100618

Zhang, X., Li, S., and Niu, S. (2020). ACE2 and COVID-19 and the Resulting ARDS. Postgrad. Med. J. 96 (1137), 403-407. doi: 10.1136/postgradmedj-2020137935

Zhao, Y., Liu, X., Qu, Y., Wang, L., Geng, D., Chen, W., et al. (2019). The Roles of $\mathrm{P} 38 \mathrm{MAPK} \rightarrow \mathrm{COX} 2$ and NF- $\mathrm{Kb} \rightarrow \mathrm{COX} 2$ Signal Pathways in Age-Related Testosterone Reduction. Sci. Rep. 9 (1), 10556. doi: 10.1038/s41598-019-46794-5
Zhao, Y. T., Qi, Y. W., Hu, C. Y., Chen, S. H., and Liu, Y. (2016). Advanced Glycation End Products Inhibit Testosterone Secretion by Rat Leydig Cells by Inducing Oxidative Stress and Endoplasmic Reticulum Stress. Int. J. Mol. Med. 38 (2), 659-665. doi: 10.3892/ijmm.2016.2645

Conflict of Interest: The authors declare that the research was conducted in the absence of any commercial or financial relationships that could be construed as a potential conflict of interest.

Publisher's Note: All claims expressed in this article are solely those of the authors and do not necessarily represent those of their affiliated organizations, or those of the publisher, the editors and the reviewers. Any product that may be evaluated in this article, or claim that may be made by its manufacturer, is not guaranteed or endorsed by the publisher.

Copyright $\odot 2021$ Al-kuraishy, Al-Gareeb, Faidah, Alexiou and Batiha. This is an open-access article distributed under the terms of the Creative Commons Attribution License (CC BY). The use, distribution or reproduction in other forums is permitted, provided the original author(s) and the copyright owner(s) are credited and that the original publication in this journal is cited, in accordance with accepted academic practice. No use, distribution or reproduction is permitted which does not comply with these terms. 